\title{
Research on Inspection and Grade Evaluation of Product Quality Based on Fuzzy Mathematics
}

\author{
Yanhong Sun ${ }^{1, a}$, Kun Liang ${ }^{1, b}$,Chunyu Mao ${ }^{1, c^{*}}$, and Xinxin Gao ${ }^{1, d}$ \\ ${ }^{1}$ College of Mechanical Engineering, Jilin Engineering Normal University, Changchun 130052, \\ China \\ a 343175460@qq.com, ${ }^{b} 1178873392 @ q q . c o m$, \\ c290414003@qq.com, d1551109305@qq.com \\ *The corresponding author
}

Keywords: Evaluation Index System; Quality Inspection; Grade Evaluation; Test Statistic; Maximum Closeness Principle

\begin{abstract}
Based on the switching power supply as an example, through the establishment of evaluation index system of switching power supply quality, the weight coefficient of each evaluating indicator is given by experts using the cycle calculation method and the direct digitization method as the basis for quality inspection. Based on the theory of probability statistics, the quality test statistic is constructed, which can be used to test whether the product is qualified or not. The maximum closeness principle of fuzzy mathematics is introduced into the product quality ranking. Quantitative analysis of product quality is easy to analyze and evaluate product grade. These studies provide reference for the selection of outsourcing parts to evaluate product quality level, to improve utilization of ancillary products to further improve the quality of purchased or the quality of the whole system, and for the enterprise or the factory bring more economic benefits.
\end{abstract}

\section{Introduction}

"Quality Inspection" is the basic means of the product quality management and quality control, to measure, inspection and test the one or more quality indexes of product, and the quality standard stipulated results and compared to determine the degree with different quality characteristics[1]. Quality inspection can achieve quality control, prevention of quality problems, supervision of quality assurance conditions, feedback quality information and other functions[2]. For a large number of purchased parts such as switching power supply, product quality may be tested to distinguish between "qualified" and "unqualified", to determine whether the product quality standards. Therefore, product quality inspection is an important part to ensure the quality, but also the basis for product quality optimization, that is, from a number of qualified products to choose the best products to improve the quality level of the machine. In this paper, the switching power supply is taken as an example to evaluate the quality of products by the method of fuzzy evaluation.

\section{Determine The Research Object and Product Quality Evaluation Index System}

The switching power supply as an example, the test methods and quality grade evaluation method is used to test whether the largest weight quality index standards, to evaluate the quality. These methods are also applicable to other indicators or products, to lay the theoretical foundation for the evaluation of product quality.

Establish The Quality Index System of Switching Power Supply. Through data collection, the general product quality index is determined, and the quality index system is organized, which is a complex multi object system, the quality assessment process is a multi-objective decision problem, and the most significant features of multi-objective decision problem has two, they are the inconsistency and the contradiction between objects. The inconsistency refers to there is no uniform measurement standard among the various targets, difficult to compare, so in the multi targets comprehensive evaluation index, should be collected and normalized to a unified numerical 
transform [0, 1][3]. As shown in Fig.1.

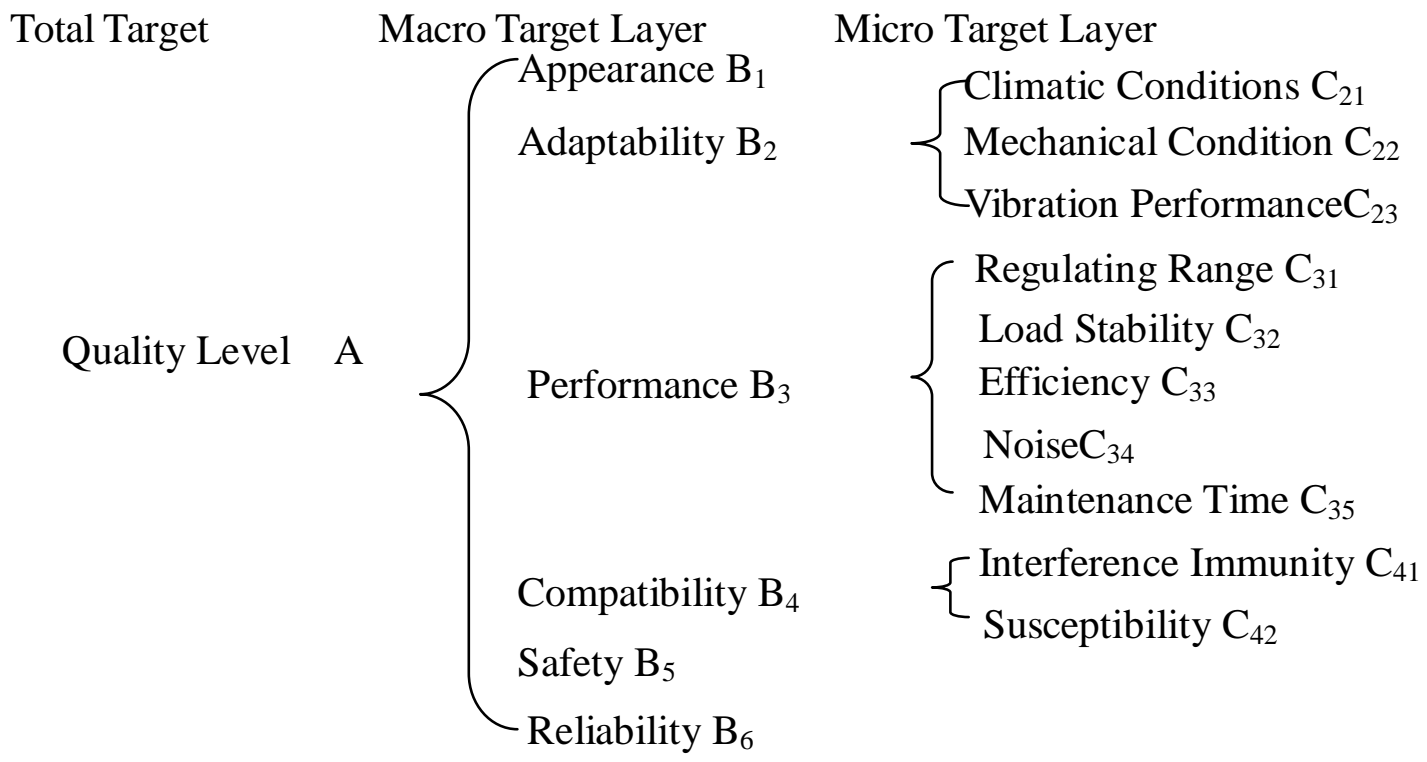

Figure 1. Quality Index System of Switching Power Supply

Weight Coefficient Assignment. The macro target layer quality index weight of switch power supply is determined by the cycle calculation method (CCM) [3], and the weight coefficient of the micro target is determined by the direct digitization method (DDM)[4].

Macro Target Layer Bi. Select 10 experts to score, an expert score is shown in Table 1.

Table 1 One Expert Score

\begin{tabular}{ccccccccc}
\hline Number & Index & 1 & 2 & 3 & 4 & 5 & 6 & Score \\
\hline 1 & Appearance & - & 0 & 0 & 0 & 0 & 0 & 0 \\
2 & Adaptability & 1 & - & 0 & 0 & 0 & 0 & 1 \\
3 & Performance & 1 & 1 & - & 1 & 1 & 0 & 4 \\
4 & Compatibility & 1 & 1 & 0 & - & 1 & 0 & 3 \\
5 & Safety & 1 & 1 & 0 & 0 & - & 0 & 2 \\
6 & Reliability & 1 & 1 & 1 & 1 & 1 & - & 5 \\
Total & & & & & & & & 15 \\
\hline
\end{tabular}

The results of ten experts scoring summary, after normalization, the weight index of the quality indicators are shown in Table 2.

Table 2 Weight Index of Macro Target Layer

\begin{tabular}{ccccccc}
\hline Index & Appearance & Adaptability & Performance & $\begin{array}{c}\text { Compati } \\
\text {-bility }\end{array}$ & Safety & Reliability \\
\hline Weight & 0.0267 & 0.0800 & 0.3000 & 0.1867 & 0.0933 & 0.3133 \\
\hline
\end{tabular}

Micro Target Layer $\mathrm{B}_{\mathrm{i}}--\mathrm{C}_{\mathrm{ij}}(\mathrm{i}=2,3,4 ; \mathrm{j}=1,2,3,4,5)$. After the consistency test and the normalization, the conclusion is drawn, as shown in Table 3. 
Table 3 Weight Index of Micro Target Layer

\begin{tabular}{ccc}
\hline $\mathrm{B}_{\mathrm{i}}$ & $\mathrm{C}_{\mathrm{ij}}$ & Weight \\
\hline \multirow{3}{*}{ Adaptability } & Climatic Conditions & 0.1900 \\
& Mechanical Condition & 0.4158 \\
& Vibration Performance & 0.3942 \\
& Regulating Range & 0.0820 \\
Performance & Load Stability & 0.1537 \\
& Efficiency & 0.3812 \\
& Noise & 0.2146 \\
Compatibility & Maintenance Time & 0.1685 \\
& Interference Immunity & 0.5000 \\
& Susceptibility & 0.5000 \\
\hline
\end{tabular}

Through observing the weight coefficient, we find that the reliability of switching power supply has the greatest impact on the quality of the product. In the national standard, the average time before failure(MTTF) is used to measure the reliability of switching power supply[5,6].

\section{Reliability Quality Inspection and Quality Classification of Switching Power Supply}

Quality Inspection. In this case, 9 samples were randomly selected. The test data of the switching power supply are shown in Table 4.

Table 4 Samples

\begin{tabular}{cccccccccc}
\hline Sample & 1 & 2 & 3 & 4 & 5 & 6 & 7 & 8 & 9 \\
\hline $\operatorname{MTTF}\left(\mathrm{x}_{\mathrm{i}}\right)[\mathrm{h}]$ & 2985 & 2997 & 3100 & 3526 & 3645 & 3350 & 3110 & 3078 & 3025 \\
\hline
\end{tabular}

It is observed that the data obey normal distribution. Calculate the sample average $\bar{x}$, sample standard deviation $\mathrm{S}$ and the population average $\mu$.

$$
\bar{x}=\frac{1}{n} \sum_{i=1}^{n} x_{i}=3201.77 ; \quad S=\frac{1}{n-1} \sum_{i=1}^{n}\left(x_{i}-\bar{x}\right)^{2}=244.39 ; \quad \mu=3000 \text { [7] }
$$

Structural test statistic: $Q_{L}=(\bar{x}-\mu) / S=0.8256<k(2.11)$

It is indicated that the reliability index of the switch power supply meets the requirements of the national standard and the quality is qualified.

Product Quality Grade Evaluation of Switching Power Supply Based on Fuzzy Mathematics. The quality index system of product is a complex system of multiple indicators multiple levels, some can be described quantitatively, but most can not be described quantitatively. Reliability of the switching power supply is not a quantitative description of the fuzzy boundary, so product quality grade evaluation of switching power supply based on Fuzzy Mathematics is conducted.

The set of factors $A$ is composed of various quality indexes, $A=\left(a_{1} a_{2} \cdots \cdots a_{n}\right)=\left(a_{i}\right)=\{$ Appearance, Adaptability, Performance, Compatibility, Safety, Reliability\}; The set of factors B is composed of

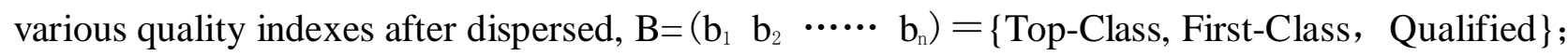
Evaluation set is $\mathrm{G}=\left(\begin{array}{lllll}g_{1} & g_{2} & \cdots & \cdots & g_{n}\end{array}\right), n=3$ 。Three evaluation sets are obtained 。

$$
G_{1}=\left[\begin{array}{ccc}
1 & 0 & 1 \\
0.2136 & 0.4237 & 0.3620 \\
0.4200 & 0.1760 & 0.4040 \\
0.3180 & 0.3120 & 0.3700 \\
0.5000 & 0 & 0.5000 \\
0 & 1 & 0
\end{array}\right] \quad G_{2}=\left[\begin{array}{ccc}
0.5100 & 0.3060 & 0.1840 \\
0.2170 & 0.3000 & 0.4830 \\
0.3640 & 0.4560 & 0.1800 \\
0.5000 & 0.5000 & 0 \\
0.0900 & 0.2100 & 0.7000 \\
0.0540 & 0.8210 & 0.1250
\end{array}\right] \quad G_{2}=\left[\begin{array}{ccc}
0.7800 & 0 & 0.2200 \\
0.2407 & 0.4032 & 0.3561 \\
0.5000 & 0.1700 & 0.3300 \\
0.1350 & 0.7950 & 0.0700 \\
0.7000 & 0 & 0.3000 \\
0.2100 & 0.6500 & 0.1400
\end{array}\right]
$$

The weight sets include $\mathrm{Wa}$ and $\mathrm{W}_{\mathrm{b}} \mathrm{Wa}=\left[\begin{array}{llll}0.080 & 0.300 & 0.1867 & 0.0933\end{array}\right], \mathrm{W}_{\mathrm{b}}=\left[\begin{array}{lll}0.3678 & 0.2541\end{array}\right.$ 0.3781]. According to the eigenvalue matrix[7、8], calculate the switching power quality index 
membership matrix $\mathrm{R}$, the matrix will be normalized, that is $\mathrm{R}$ '.

$$
R=W_{a} \bullet G^{T}=\left(\begin{array}{lll}
\omega_{g 1} \omega_{g 2} & \omega_{g 3}
\end{array}\right)\left(\begin{array}{l}
G_{1} \\
G_{2} \\
G_{3}
\end{array}\right)=\left[\begin{array}{ccc}
0.7922 & 0.3781 & 0.1299 \\
0.2246 & 0.3844 & 0.3907 \\
0.4358 & 0.2447 & 0.3189 \\
0.2949 & 0.5422 & 0.1624 \\
0.4713 & 0.1270 & 0.2973 \\
0.093 & 0.8221 & 0.0666
\end{array}\right] \quad R^{\prime}=\left[\begin{array}{ccl}
0.6093 & 0.2908 & 0.0999 \\
0.2246 & 0.3845 & 0.3909 \\
00.4360 & 0.2448 & 0.3192 \\
0.2950 & 0.5424 & 0.1626 \\
0.5262 & 0.1418 & 0.3320 \\
0.0947 & 0.8374 & 0.0686
\end{array}\right]
$$

According to the concept of fuzzy evaluation, the evaluation vector $\mathrm{S}$ is get,

$$
S=W_{a} \bullet R^{\prime}=\left[\begin{array}{lll}
0.2983 & 0.4885 & 0.2102
\end{array}\right]=\left(\begin{array}{lll}
S_{1} & S_{2} & S_{3}
\end{array}\right)
$$

According to the result of fuzzy evaluation $S$, based on the Maximum Closeness Principle[9、10], the product quality is graded.

$\mathrm{S}_{\mathrm{k}}=\max S_{i}, \quad \sum_{i=1}^{k-1} s_{i}$ and $\sum_{i=k+1}^{m} s_{i}$ are calculated, if the two are less than $\frac{1}{2} \sum_{i=1}^{m} s_{i}, \mathrm{~S}_{k}$ as a result of evaluation; If $\sum_{i=1}^{k-1} s_{i} \geqslant \frac{1}{2} \sum_{i=1}^{m} s_{i}$ (or $\left.\sum_{i=k+1}^{m} s_{i} \geqslant \frac{1}{2} \sum_{i=1}^{m} s_{i}\right), \quad \mathrm{S}_{k-1}\left(\right.$ or $\left.\mathrm{S}_{k+1}\right)$ as a result of evaluation。

If there are $\mathrm{q}(\leqslant 3)$ the equal maximum number in the data of $S=\left(\mathrm{s}_{1}, \mathrm{~s}_{2} \ldots \ldots \mathrm{s}_{\mathrm{n}}\right)$, according to the provisions (1) were calculated as the first shift, after shifting the discrete comments, take the center of the assessment; If the center comments have two, then take the weight of the location of the evaluation comments.

In this paper, $\mathrm{S}_{2}=\max S_{i}$, so $\mathrm{k}=2 . \frac{1}{2} \sum_{i=1}^{m} s_{i}=\frac{1}{2}(0.2983+0.4885+0.2102)=0.498$.

Thus it can be seen, $\quad \mathrm{s}_{1}<\frac{1}{2} \sum_{i=1}^{m} s_{i}, \quad \mathrm{~s}_{3}<\frac{1}{2} \sum_{i=1}^{m} s_{i}, \quad \mathrm{~s}_{2}$ is a result of evaluation, the switching power supply was designated as the first grade, can guarantee the quality of work of the equipment requirements.

\section{Conclusion}

The quality evaluation index system of switching power supply is determined, which is the theoretical basis for evaluating its quality.

By using the theory of probability and statistics, the method of quality test statistic is constructed to test the quality of products.

By constructing and calculating the quality evaluation vector, according to the Maximum Closeness Principle of fuzzy mathematics can effectively judge the product quality level.

\section{References}

[1] S.S. Li: Evaluation Method of Shale Pressure Based on AHP, (Ph.D., Northeast Petroleum University, China 2016), p15(In Chinese)

[2] Z.Ye: Research and application of fuzzy comprehensive evaluation method based on AHP ,( Ph.D., South China University of Technology, China 2010) , p42(In Chinese)

[3] S.F. Liu, B.H. Guo: System evaluation: methods, models and Applications (Science Press, China 2015)

[4] H.Y. Jing, L. Zhang and B.C. Wen: Journal of Northeastern University ( Natural Science), Vol.30 (2009) No.5, p712

[5] Y.T. Zhang, X.C. Zhang, M.S. Jia and X.S. Xue: Journal of Beihang University , vol. 30(2016) No.5,p1065.

[6] T. Jun and Z. Jie: Reliability Engineering and System Safety, Vol. 50 (1995) No.8, p7

[7] S.S. Mao, X.L. Liu: Mathematical Statistics (Renmin University of China press, China 2016) 
[8] Z.Q. Yao, L.J. Zhang, A.B. Xiong: Mathematics in Practice and Theory, Vol. 18 (2016) No.6, p176. (In Chinese)

[9] L. Zhang, S. Cao, S.X. Li, L.S. Xu and Q.W. Li: Chinese Journal of Health Statistics, Vol. 45 (2016) No.1, p.154. (In Chinese)

[10] Q.P. Wang,D.H. Zhang, P. Li: Journal of Xian University of Technology, Vol. 21 (2005) No.4, p.437. (In Chinese) 